\title{
Seismic Analysis of Coupled High-Speed Train-Bridge with the Isolation of Friction Pendulum Bearing
}

\author{
Xinmin Hong, Wenhua Guo $(\mathbb{D}$, and Zihao Wang \\ School of Civil Engineering, Central South University, Tianxin District, Changsha 410075, China \\ Correspondence should be addressed to Wenhua Guo; gwh_work@163.com
}

Received 15 October 2019; Accepted 4 February 2020; Published 24 February 2020

Academic Editor: Valeria Vignali

Copyright ( 2020 Xinmin Hong et al. This is an open access article distributed under the Creative Commons Attribution License, which permits unrestricted use, distribution, and reproduction in any medium, provided the original work is properly cited.

\begin{abstract}
The paper presents a framework for the seismic analysis of the coupled high-speed train-bridge with the isolation of friction pendulum bearing (FPB). Taking the rail irregularities as system's self-excitation with the seismic as external excitation, the equation of motion of the train-bridge coupled system under earthquake is built up. A five-span simple-supported railway bridge is taken as an example, and the computer simulation method is used to establish the dynamic model of the train-bridge system with the isolation of FPB under earthquake. A train composed of eight 4-axle coaches of 35 degrees-of-freedom (DOF) is considered, and FPB is simulated by a force element which includes both nonlinear spring and damper characteristics and a hysteresis function. Backward differentiation formula and the mode superposition method are adopted in the calculation of coupling vibration of the train-bridge system. The dynamic responses of the train running on the bridge with the isolation of FPB and with the common spherical bearing (CSB) under earthquake are studied. The results show that FPB with a friction coefficient no less than 0.05 , instead of CSB, can reduce the dynamic response of the train greatly; the faster the train speed and the higher the pier, the greater the effect of FPB. However, FPB may increase the dynamic response of the train when the seismic intensity exceeds $0.14 \mathrm{~g}$.
\end{abstract}

\section{Introduction}

By the end of 2018, China has over 29,000 km of high-speed railway (HSR) lines in service [1]. With the upgrade of railway design standards, elevated bridges stretching tens of kilometers are built to ensure the smoothness of the track and the safety and stability of running trains, which greatly increased the probability of trains traveling on the bridge when earthquakes occur. Even earthquakes that do not threat the safety of bridges can jeopardize the operation of trains [2]. As shown in Figure 1, in the short decades of HSR, there have been three train derailments due to earthquake action when the trains are running on bridges [3-5]. The safety of HSR trains traveling on bridges during earthquakes is an issue of great study interest in many countries, especially those in earthquake-prone regions, such as China and Japan. However, most of the previous studies have been focused on the influence of bridge parameters on the safety of trains running on bridges under earthquake $[6,7]$ or the effect of seismic intensity on the safety of trains running on bridges [8-10] and without considering the isolation of FPB. FPB was put forward by Zays, professor of the University of California, in 1985. FPB is widely used on bridges, thanks to their isolation period independent of the superstructure mass, their high dissipation and recentering capacity, and their longevity and durability characteristics $[11,12]$. The seismic performance of FPB has been investigated in many experimental and numerical studies [13, 14]. Most of these studies have been concerned on highway bridges rather than high-speed railway bridges [15-17] or the seismic response of bridges isolated by FPB under earthquake without the trains $[18,19]$. Very little information is publicly available of seismic responses of trains traveling on the bridge with the isolation of FPB under earthquake action. To ensure the safety of running trains, such as a complicated dynamic interaction among vehicles, seismic and bridge with the 


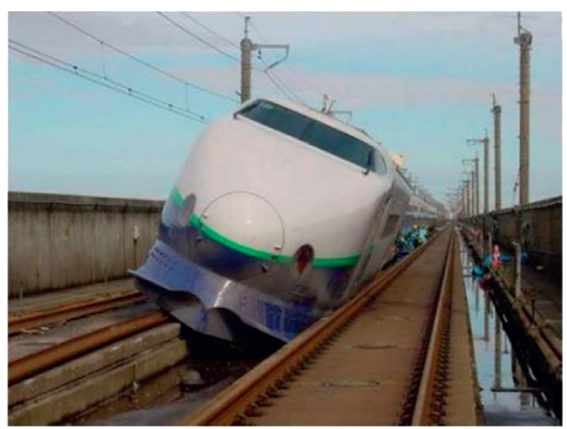

(a)

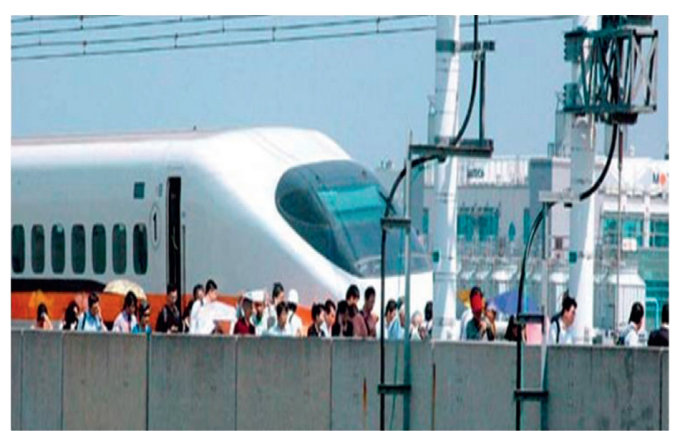

(b)

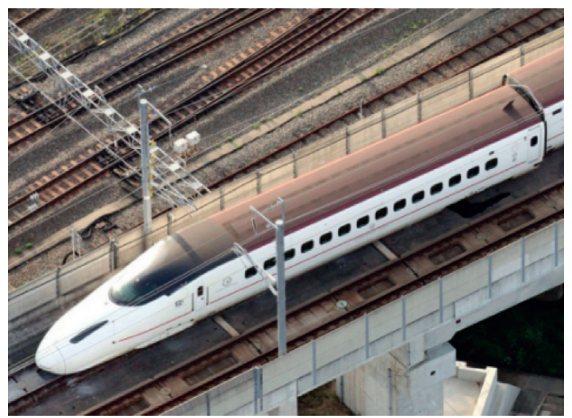

(c)

FIGURE 1: Derailment of HSR trains on bridges due to earthquakes. (a) Niigata Chuetsu earthquake in Japan. (b) Jiashian earthquake in Taiwan. (c) Kumamoto earthquake in Japan.

isolation of FPB should be carefully and timely investigated.

Based on the multibody dynamics theory and the finite element method, a three-dimensional train-bridge interaction model considering the isolation of FPB under earthquake is present in this study. A five-span simply supported girder bridge and a group high-speed train consisting of eight vehicles are selected as study objects; the influence of train speed, seismic intensity, and pier height on the dynamic responses of train running on bridge with the isolation of FPB or with CSB under earthquake is calculated. The sensitivity of the friction coefficient and the curvature radius of $\mathrm{FPB}$ to the dynamic response of the trains are analyzed. The main goal of this study is to clarify the dynamic characteristics of trains running on the bridge with the isolation of FPB under earthquake and provide some useful values for the seismic isolation design of FPB of the simply supported girder bridge in HSR.

\section{Model of the Coupled System of Train-Bridge}

2.1. Model of the Train. The train subsystem model is composed of several locomotives and passenger cars. Each vehicle model is a multi-degrees-of-freedom vibration system composed of a car body, two bogies, four wheel sets, and the spring-damper suspensions [20]. The car body and the bogies are linked by the second suspension system, and the bogies and the wheels are linked by the primary suspension system. Each rigid body has five DOFs, including lateral swing, vertical floating, rolling, yawing, and pitching movements. In total, each single vehicle has 35 DOFs as shown in Figure 2.
The following assumptions are adopted in modeling the vehicle subsystem:

(1) The car body, bogies, and wheel sets are regarded as rigid components, neglecting their elastic deformation during vibration

(2) The vehicle element is a linear system, namely, the mass, damping, and stiffness matrices of the vehicle element are regarded as constant matrices in the analysis process

(3) The train runs on the bridge at a constant speed, while the movement of the train under starting, braking, or accelerating state is neglected; thus, the DOFs in the longitudinal direction for the car body, bogies, and wheel sets are not considered

(4) The wheel set, bogie, and car body are all subjected to microvibration

(5) All springs are linear, and all dampings are calculated by viscous damping, and creep force is calculated by linear

\subsection{Model of the Bridge System}

2.2.1. Model of the Bridge. The simply supported railway bridge is composed of piers, girders, rails, and accessory structures. Spatial beam element model is used for girders, rails, and piers, and the rails are regarded as Euler beam supported by discrete elastic points. The connection between the track and the main girder is regarded as the fastener force, which is considered in the form of a spring-damper 


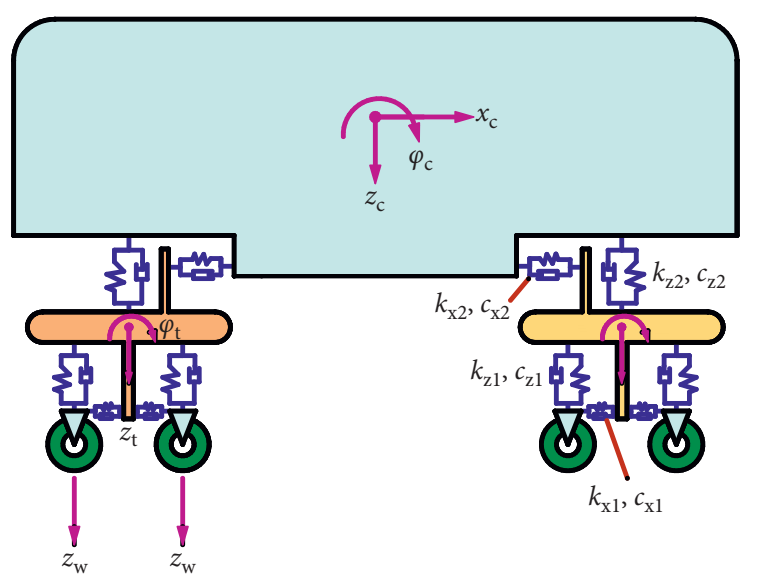

(a)

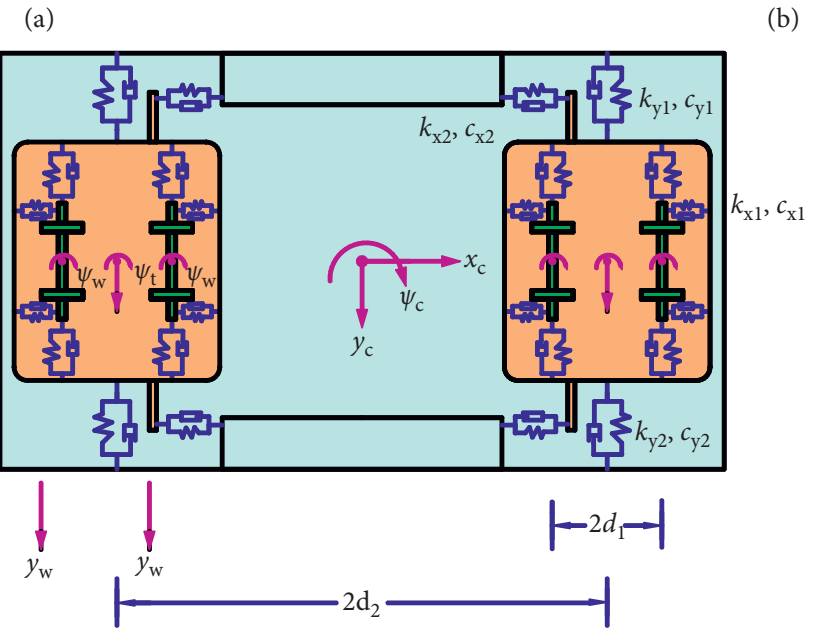

(c)

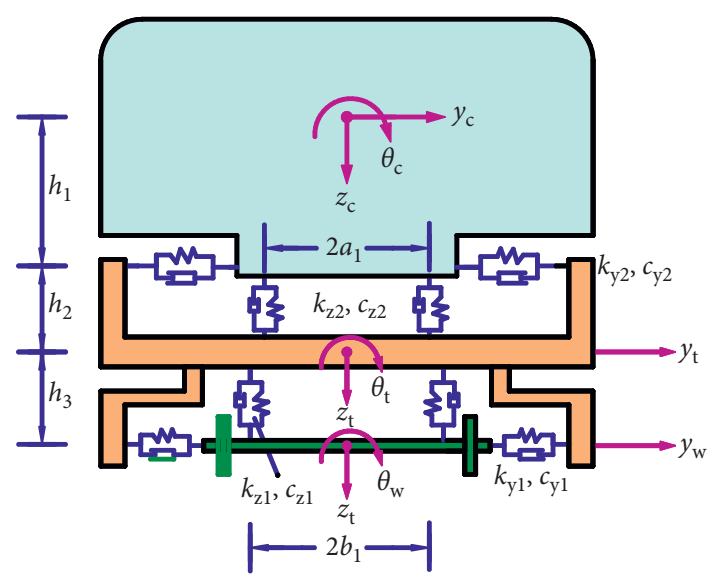

(b)

Figure 2: Side, bottom, and rear view of the vehicle model exhibiting 35 DOFs.

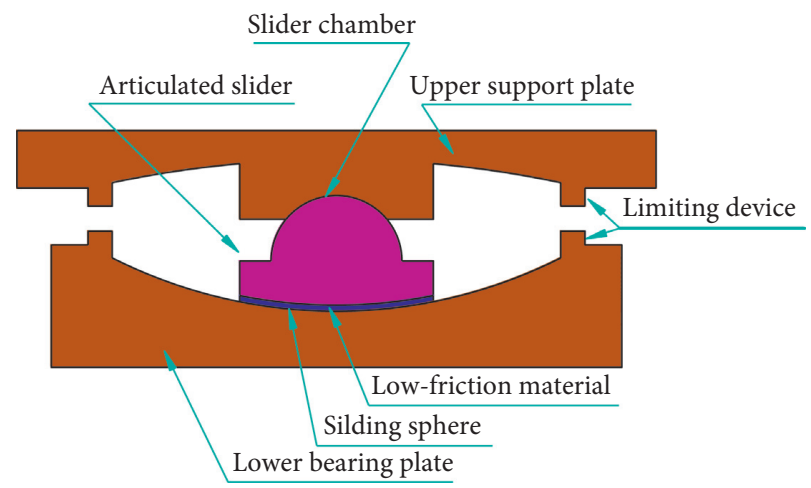

FIGURE 3: Structural sketch of FPB.

element in the horizontal and vertical directions. The stiffness of the pier foundation is superimposed on the corresponding joints. The damping of the bridge system is considered as Rayleigh damping; generally, the corresponding damping ratio of low-order frequency is $2 \% \sim 5 \%$. The mass of accessory structures is added into the mass of the girders.

\subsubsection{Model of the Bearing}

(1) Common Spherical Bearing. Spherical steel bearings are commonly used in railway bridges. The rigidity of the bearings is large and can meet the rigidity requirements of railway bridges very well. The degrees of freedom in the movable direction of the spherical steel bearing are released, 


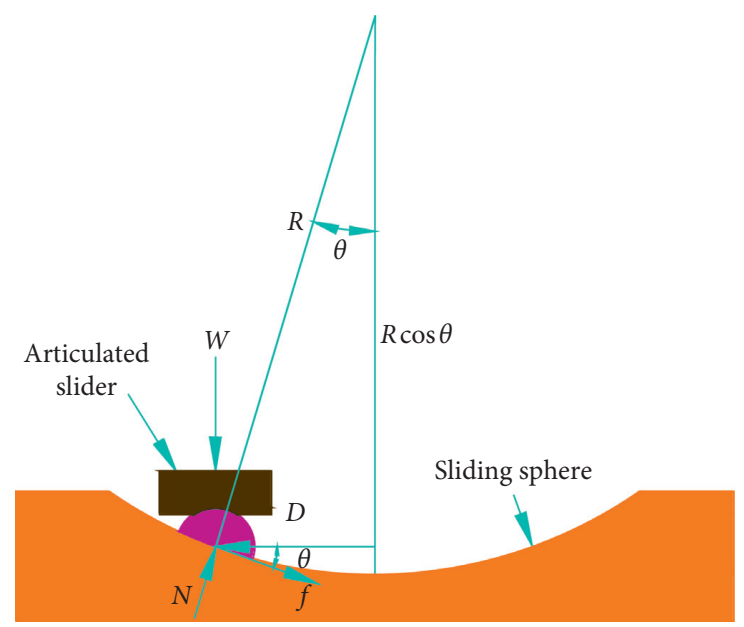

Figure 4: Schematic diagram of the simple pendulum model.

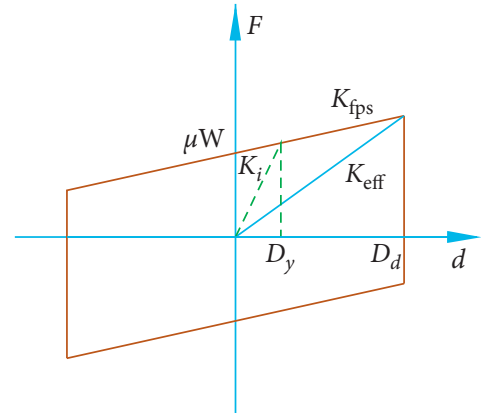

(a)

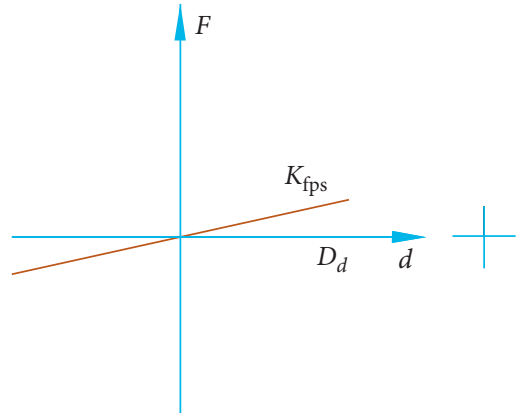

(b)

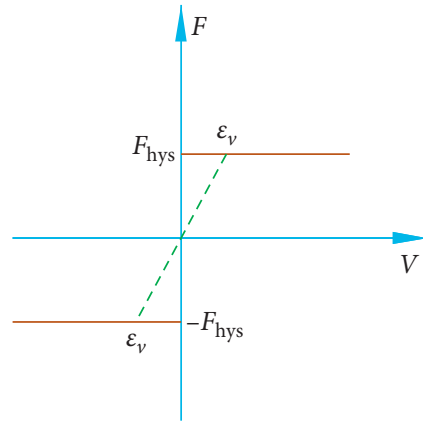

(c)

FIGURE 5: Load-displacement hysteresis curve of FPB.

and the degrees of freedom in the nonmovable direction are realized by master-slave restraint.

(2) Model of FPB. The FPB, as shown in Figure 3, is developed on the basis of spherical steel bearings; it is a vibration isolation device which dissipates energy by friction [21]. Based on the principle of pendulum, a simple pendulum motion occurs in the upper structure through the motion of spherical friction pairs, and energy is dissipated by friction damping during the swing process. The restoring force provided by the swing device can make the bearing return to the central position. The schematic diagram of FPB is shown in Figure 4.

The restoring force $F$ of the bearing can be approximately expressed as

$$
F=\frac{W D}{R \cos \theta}+\frac{\mu N \operatorname{sgn} \dot{\theta}}{\cos \theta},
$$

where $W$ is the vertical load supported by the bearing, $D$ is the horizontal displacement of the bearing and is equal to the relative horizontal displacement between the upper and lower bearing plates for a FPB, and $\theta$ and $\dot{\theta}$ are sliding angle and sliding angular velocities, respectively; $R$ is the curvature radius and is the distance between the centers of the spherical rotation surface and the spherical sliding surface, $\mu$ is the friction coefficient of the friction pairs on the sliding spherical surface, and $N$ is the compressive force between the upper plate and the slider and is perpendicular to the spherical sliding surface and points to the center of the slider. $\operatorname{sgn} \dot{\theta}$ is the sign function given as

$$
\operatorname{sgn} \dot{\theta}= \begin{cases}1, & \dot{\theta}>0, \\ -1, & \dot{\theta}<0 .\end{cases}
$$

In practical engineering, when $\theta<5^{\circ}$, equation ( 1 ) can be written in a simplified form as

$$
F=\frac{W D}{R}+\mu W \operatorname{sgn} \dot{\theta} .
$$

The lateral stiffness of the bearing $K_{\mathrm{fps}}$ is almost unchanged after the surfaces begin to slide and is given as

$$
K_{\mathrm{fps}}=\frac{W}{R} .
$$

As displayed in Figure 5, the restoring force $F$ in the loaddisplacement hysteresis curve model of FPB can be regarded as the effect of a nonlinear spring combined with a constant hysteresis force.

The parameters of the nonlinear spring and the constant hysteresis force can be given as 


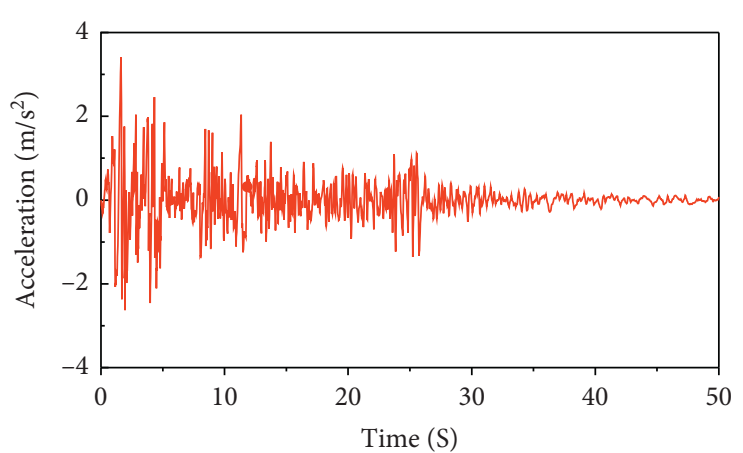

(a)

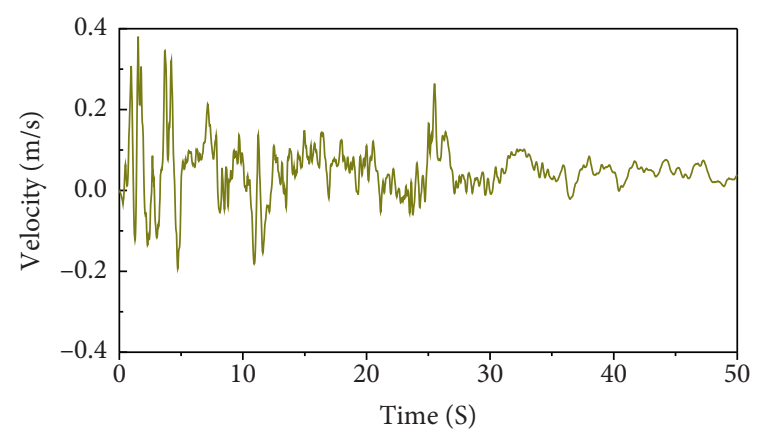

(c)

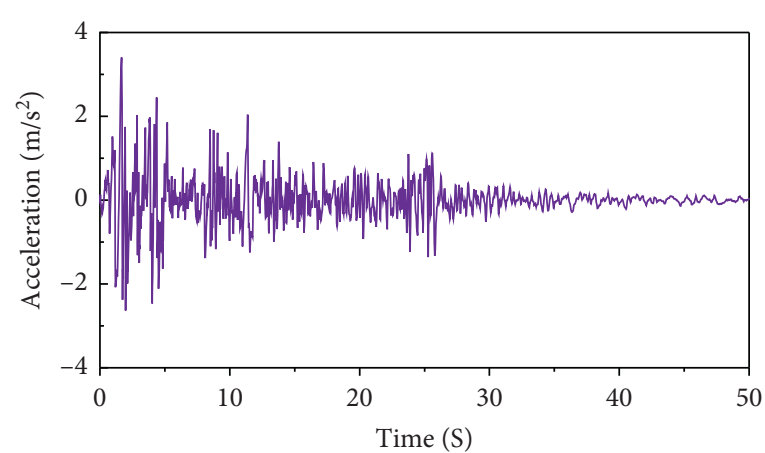

(b)

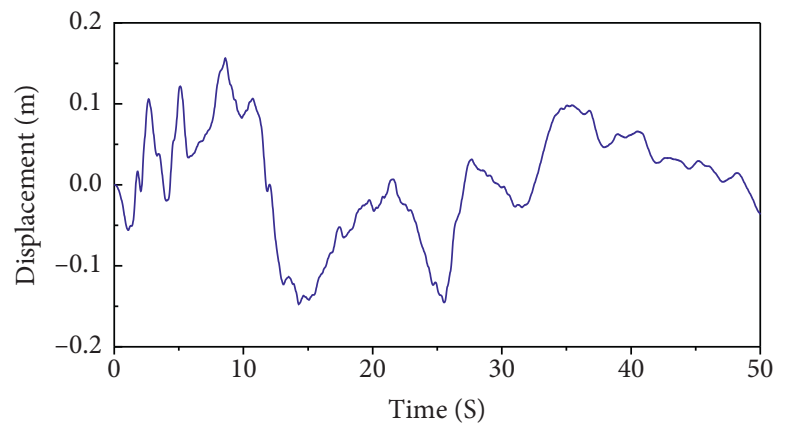

(d)

Figure 6: Acceleration, velocity, and displacement time histories of the seismic wave. (a) Original acceleration time history of the seismic wave. (b) Modified acceleration time history of the seismic wave. (c) Modified velocity time history of the seismic wave. (d) Modified displacement time history of the seismic wave.

$$
\begin{aligned}
K_{\mathrm{eff}} & =\frac{F}{D_{d}}=\frac{W}{R}+\frac{\mu W}{D_{d}}, \\
K_{1} & =K_{\mathrm{fps}}=\frac{W}{R}, \\
F_{\mathrm{hys}} & =\mu W, \\
\varepsilon_{v} & =\dot{D}_{y}, \\
v & =R \cdot \dot{\theta}, \\
F & = \begin{cases}\frac{W D}{R} \pm \mu W, & \text { if }|v| \geq \varepsilon_{v}, \\
\frac{W D}{R}+\frac{v}{\varepsilon_{v}} \mu W, & \text { if }|v|<\varepsilon_{v},\end{cases}
\end{aligned}
$$

where $D_{y}$ is the initial yield displacement of the bearing, $\varepsilon_{v}$ is the sliding velocity corresponding to the $D_{y}$ of the bearing, $v$ is the sliding velocity, $K_{1}$ is the stiffness of the spring, $F_{\text {hys }}$ is the constant hysteresis force, $D_{d}$ is the ultimate displacement of the bearing, $K_{i}$ is the initial stiffness of the bearing, and $K_{\text {eff }}$ is the equivalent stiffness of the bearing.

Seismic energy is dissipated by the friction action of the friction pairs. The capacity of seismic energy dissipation is evaluated by the factor of the effective damping ratio $\beta_{\text {eff }}$ :

2.3. Model of Rail Irregularity. Rail irregularities are a major source of train vibrations and play a very important role on the dynamic interaction analysis of the train-bridge system, which may enlarge the train's derailment during seismic loading. At present, based on the statistical analysis of a large number of measured data, scholars have fitted the power spectral density (PSD) functions of various types of rail irregularities, and Zhai [22] analyzed and compared the typical rail spectra at home and abroad. The rail irregularity spectra in German high-speed railways are currently applied in European railways, which are also adopted in China to analyze the running stability of trains according to the overall technical conditions for high-speed trains. The German track irregularity spectra are expressed as

$$
\begin{aligned}
& S_{v}(\Omega)=\frac{A_{v} \Omega_{c}^{2}}{\left(\Omega^{2}+\Omega_{r}^{2}\right)\left(\Omega^{2}+\Omega_{c}^{2}\right)}, \\
& S_{a}(\Omega)=\frac{A_{a} \Omega_{c}^{2}}{\left(\Omega^{2}+\Omega_{r}^{2}\right)\left(\Omega^{2}+\Omega_{c}^{2}\right)}, \\
& S_{c}(\Omega)=\frac{A_{v} \cdot b^{-2} \cdot \Omega_{c}^{2} \cdot \Omega^{2}}{\left(\Omega^{2}+\Omega_{r}^{2}\right)\left(\Omega^{2}+\Omega_{c}^{2}\right)\left(\Omega^{2}+\Omega_{s}^{2}\right)}, \\
& S_{g}(\Omega)=\frac{A_{g} \Omega_{c}^{2} \Omega^{2}}{\left(\Omega^{2}+\Omega_{r}^{2}\right)\left(\Omega^{2}+\Omega_{c}^{2}\right)\left(\Omega^{2}+\Omega_{s}^{2}\right)},
\end{aligned}
$$




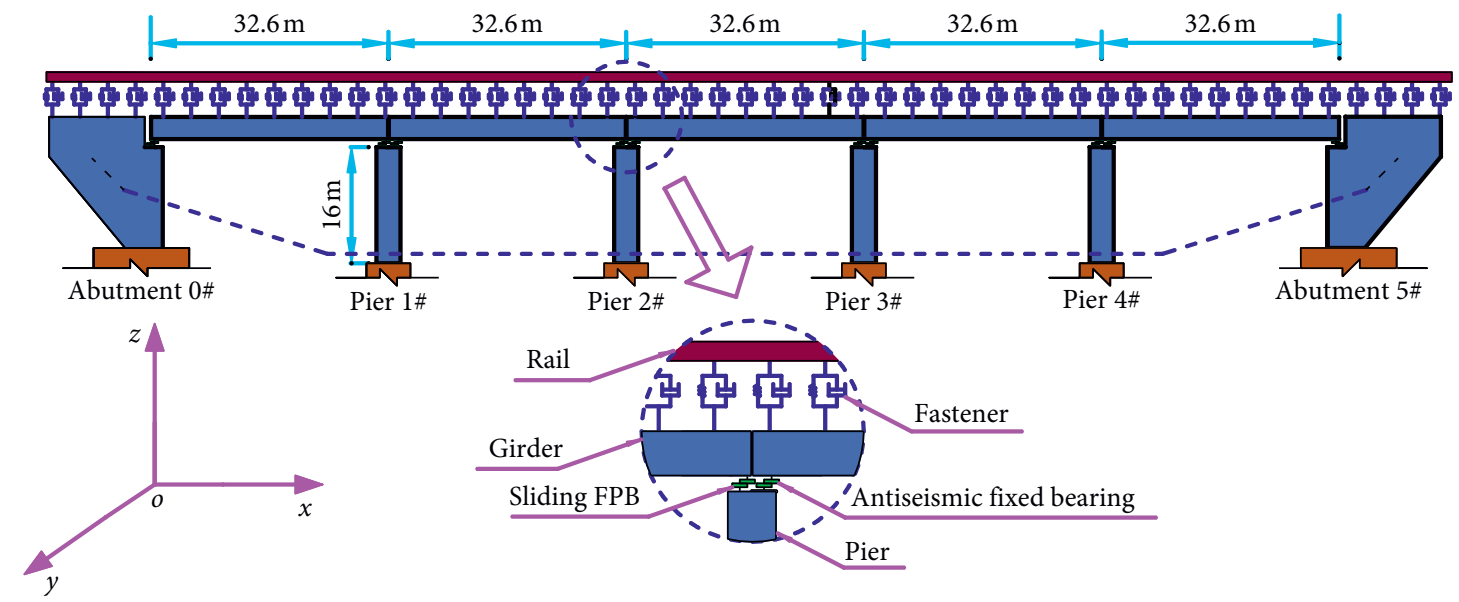

FIGURE 7: Schematic of the five-span simply supported bridge.

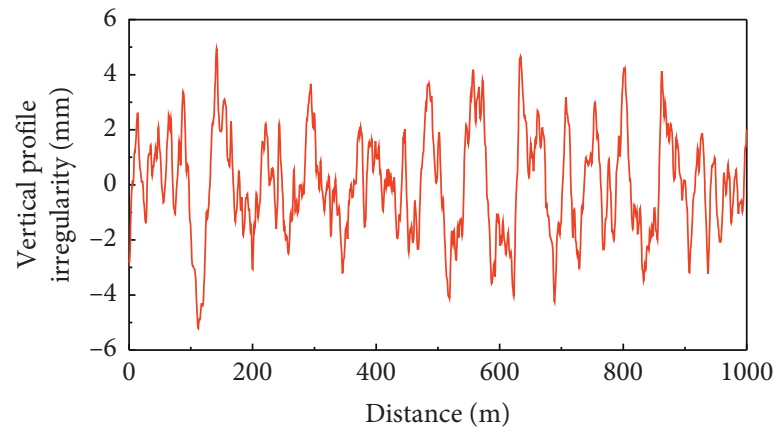

(a)

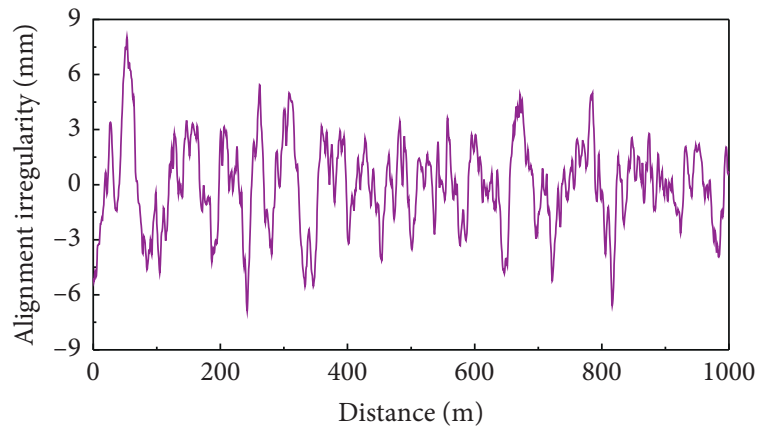

(b)

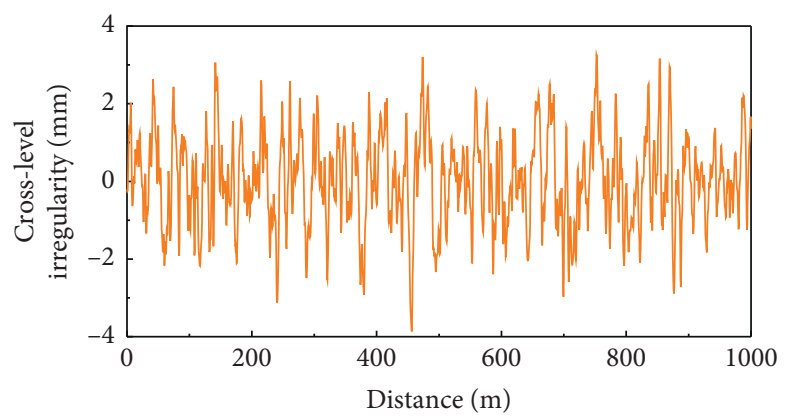

(c)

FIGURE 8: Irregularity sample of the rail. (a) Vertical profile irregularity. (b) Alignment irregularity. (c) Cross-level irregularity.

where $S_{v}(\Omega), S_{a}(\Omega)$, and $S_{g}(\Omega)$ are the PSD functions of vertical profile, alignment, and gauge irregularities $\left(\mathrm{m}^{2} /(\mathrm{rad} / \mathrm{m})\right)$ and $S_{c}(\Omega)$ is the PSD function of cross-level irregularity $(1 /(\mathrm{rad} / \mathrm{m})) ; \Omega_{c}, \Omega_{r}$, and $\Omega_{s}$ are the cutoff frequencies $(\mathrm{rad} / \mathrm{m})$, $A_{a}, A_{v}$, and $A_{g}$ are the roughness coefficients $\left(\mathrm{m}^{2} \cdot \mathrm{rad} / \mathrm{m}\right), b$ is the half of the distance between the right and left rail centers, and $\Omega$ is the spatial frequency of rail irregularity $(\mathrm{rad} / \mathrm{m})$.

\section{Coupled System of Train-Bridge under Earthquake}

3.1. Modification of Earthquake Excitation. In the calculation of spatial vibration of the train-bridge interaction system under seismic load, besides the acceleration time history of the seismic wave, the velocity and displacement time history of the seismic wave should also be known in advance [23]. However, at present, the velocity and displacement time history of the seismic wave are obtained by integrating the acceleration of the seismic wave. Some low-frequency noise makes the seismograph deviate in recording the acceleration of the seismic wave. The displacement time histories will drift when it is obtained directly by quadratic integration of the acceleration time histories. Using such displacement time histories to calculate the seismic response will lead to distortion of calculation results [24]. On the basis of predecessors' study on the time-domain optimization 
TABLE 1: Main parameters of vehicles used in the case study.

\begin{tabular}{|c|c|c|c|}
\hline Parameters & Unit & Value of MC & Value of TC \\
\hline Distance of wheel sets, $2 d_{1}$ & $\mathrm{~m}$ & 2.5 & 2.5 \\
\hline Distance of bogies, $2 d_{2}$ & $\mathrm{~m}$ & 17.5 & 17.5 \\
\hline Transverse span of primary suspension, $2 b_{1}$ & $\mathrm{~m}$ & 2.0 & 2.0 \\
\hline Transverse span of secondary suspension, $2 a_{1}$ & $\mathrm{~m}$ & 2.0 & 2.0 \\
\hline Car body to secondary suspension, $h_{1}$ & $\mathrm{~m}$ & 0.54 & 0.80 \\
\hline Secondary suspension to bogie, $h_{2}$ & $\mathrm{~m}$ & 0.47 & 0.30 \\
\hline Bogie to wheel set, $h_{3}$ & $\mathrm{~m}$ & 0.08 & 0.14 \\
\hline Wheel radius, $r_{w}$ & $\mathrm{~m}$ & 0.46 & 0.46 \\
\hline Car body mass, $m_{c}$ & $\mathrm{t}$ & 48.0 & 44.0 \\
\hline Car body, $x$-inertia, $I_{x c}$ & $\mathrm{t} \cdot \mathrm{m}^{2}$ & 115 & 100 \\
\hline Car body, $y$-inertia, $I_{y c}$ & $\mathrm{t} \cdot \mathrm{m}^{2}$ & 2700 & 2700 \\
\hline Car body, $z$-inertia, $I_{z c}$ & $\mathrm{t} \cdot \mathrm{m}^{2}$ & 2700 & 2700 \\
\hline Bogie mass, $m_{t}$ & $\mathrm{t}$ & 3.2 & 2.4 \\
\hline Bogie $x$-inertia, $I_{x t}$ & $\mathrm{t} \cdot \mathrm{m}^{2}$ & 3.2 & 1.8 \\
\hline Bogie $y$-inertia, $I_{y t}$ & $\mathrm{t} \cdot \mathrm{m}^{2}$ & 7.2 & 2.2 \\
\hline Bogie $z$-inertia, $I_{z t}$ & $\mathrm{t} \cdot \mathrm{m}^{2}$ & 6.8 & 2.2 \\
\hline Wheel set mass, $m_{w}$ & $\mathrm{t}$ & 2.4 & 2.4 \\
\hline Wheel set $\mathrm{x}$-inertia, $I_{x w}$ & $\mathrm{t} \cdot \mathrm{m}^{2}$ & 1.2 & 1.1 \\
\hline Primary suspension $x$-damp/side, $c_{x 1}$ & $\mathrm{kN} \cdot \mathrm{s} / \mathrm{m}$ & 0 & 0 \\
\hline Primary suspension $y$-damp/side, $c_{y 1}$ & $\mathrm{kN} \cdot \mathrm{s} / \mathrm{m}$ & 0 & 0 \\
\hline Primary suspension $z$-damp/side, $c_{z 1}$ & $\mathrm{kN} \cdot \mathrm{s} / \mathrm{m}$ & 10 & 10 \\
\hline Secondary suspension $x$-damp/side, $c_{x 2}$ & $\mathrm{kN} \cdot \mathrm{s} / \mathrm{m}$ & 450 & 450 \\
\hline Secondary suspension $y$-damp/side, $c_{y 2}$ & $\mathrm{kN} \cdot \mathrm{s} / \mathrm{m}$ & 45 & 45 \\
\hline Secondary suspension $z$-damp/side, $c_{z 2}$ & $\mathrm{kN} \cdot \mathrm{s} / \mathrm{m}$ & 20 & 20 \\
\hline Primary suspension $x$-spring/side, $k_{x 1}$ & $\mathrm{MN} / \mathrm{m}$ & 9.0 & 15.0 \\
\hline Primary suspension $y$-spring/side, $k_{y 1}$ & $\mathrm{MN} / \mathrm{m}$ & 3.0 & 5.0 \\
\hline Primary suspension $z$-spring/side, $k_{z 1}$ & $\mathrm{MN} / \mathrm{m}$ & 1.04 & 0.7 \\
\hline Secondary suspension $x$-spring/side, $k_{x 2}$ & $\mathrm{MN} / \mathrm{m}$ & 0.24 & 0.28 \\
\hline Secondary suspension $y$-spring/side, $k_{y 2}$ & $\mathrm{MN} / \mathrm{m}$ & 0.24 & 0.28 \\
\hline Secondary suspension $z$-spring/side, $k_{z 2}$ & $\mathrm{MN} / \mathrm{m}$ & 0.40 & 0.30 \\
\hline
\end{tabular}

correction algorithm, the paper adopted the least square method to modify and fit the acceleration time histories [25]. Shown in Figure 6 are the original acceleration, modified acceleration, velocity, and displacement time histories of El Centro seismic wave, which illustrate that the velocity and displacement are approaching zeros at the end of the earthquake.

\subsection{Equation of Motion of the Train-Bridge Coupling System} under Earthquake. In the vibration analysis of the trainbridge interaction system under seismic loads, the train and bridge are regarded as an overall superstructure. The finite element method is used to establish the dynamic model of the bridge structure, the components of the bridge structure are discretized reasonably at first, and the appropriate displacement mode is selected to calculate the potential energy and strain energy of each element. According to the principle of total potential energy with stationary value in elastic system dynamics and the "set in right position" rule for formulating system matrixes [26] and taking the rail irregularities as system's self-excitation source with the seismic as external excitation, the coupling vibration equation of the train-bridge system under earthquake is built up. The seismic ground motions at various supports of the bridge are considered to be nonuniform. The equation of motion of the whole train-bridge system can be divided into blocks according to the nonsupporting nodes of the structure and the supporting nodes of the ground, given as [27].

$$
\begin{gathered}
{\left[\begin{array}{cc}
M_{s s} & M_{s b} \\
M_{b s} & M_{b b}
\end{array}\right]\left\{\begin{array}{l}
\ddot{u}_{s} \\
\ddot{u}_{b}
\end{array}\right\}+\left[\begin{array}{cc}
C_{s s} & C_{s b} \\
C_{b s} & C_{b b}
\end{array}\right]\left\{\begin{array}{l}
\dot{u}_{s} \\
\dot{u}_{b}
\end{array}\right\}+} \\
{\left[\begin{array}{cc}
K_{s s} & K_{s b} \\
K_{b s} & K_{b b}
\end{array}\right]\left\{\begin{array}{l}
u_{s} \\
u_{b}
\end{array}\right\}=\left\{\begin{array}{c}
F_{s} \\
F_{b}
\end{array}\right\},}
\end{gathered}
$$

where $M, C$, and $K$ are the mass, damping, and stiffness matrices, respectively; subscripts $s$ and $b$ denote the superstructure and bridge supports, respectively; and $\ddot{u}, \dot{u}$, and $u$ are the absolute acceleration, velocity, and displacement vectors, respectively. $F_{s}$ is the external load vectors of the superstructure, and $F_{b}$ is the reaction vectors of the supports.

When equation (8) is solved using the direct solution method, the first term on the left side of the equation is expanded, and the motion equations of the train-bridge subsystem in the absolute coordinates can be written as

$$
\begin{aligned}
& M_{s s} \ddot{u}_{s}+M_{s b} \ddot{u}_{b}+C_{s s} \dot{u}_{s}+C_{s b} \dot{u}_{b}+K_{s s} u_{s}+K_{s b} u_{b}=F_{s}, \\
& M_{b s} \ddot{u}_{s}+M_{b b} \ddot{u}_{b}+C_{b s} \dot{u}_{s}+C_{b b} \dot{u}_{b}+K_{b s} u_{s}+K_{b b} u_{b}=F_{b} .
\end{aligned}
$$

Equation (9) can be written as 


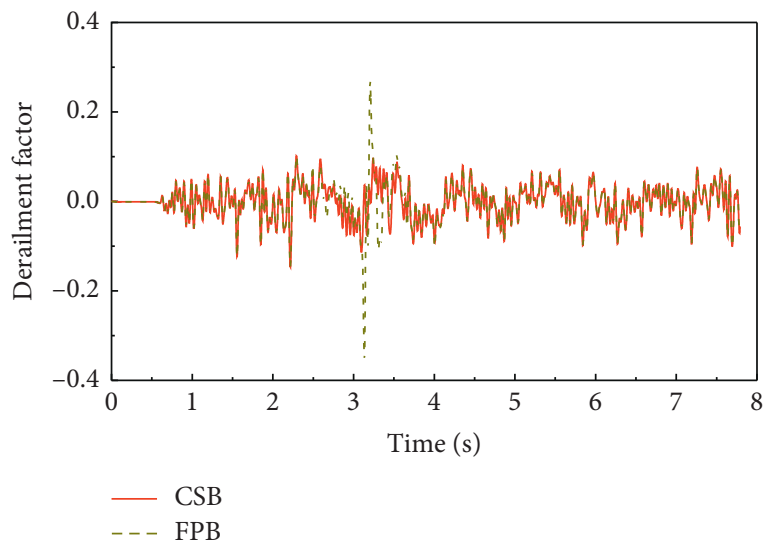

(a)

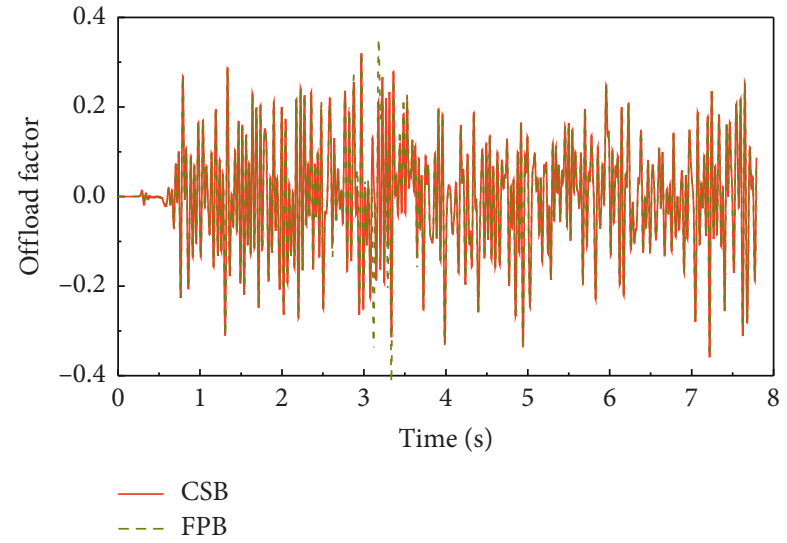

(b)

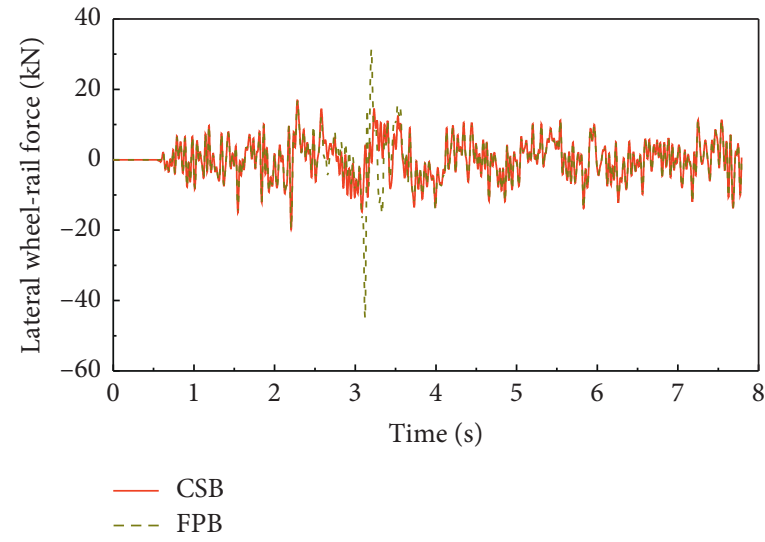

(c)

FIGURE 9: The comparison of the dynamic response of the train between FPB and CSB. (a) Derailment factor. (b) Offload factor. (c) Lateral wheel-rail force.

$$
\begin{gathered}
M_{s s} \ddot{u}_{s}+C_{s s} \dot{u}_{s}+K_{s s} u_{s}=F_{s}-F_{\text {eq }}, \\
F_{\mathrm{eq}}=M_{s b} \ddot{u}_{b}+C_{s b} \dot{u}_{b}+K_{s b} u_{b},
\end{gathered}
$$

where $F_{\text {eq }}$ is the seismic loads and $\ddot{u}_{b}, \dot{u}_{b}$, and, $u_{b}$ are acceleration, velocity, and displacement vectors of the seismic.

Usually, the influence of the term with $M_{s b}$ is significantly smaller than that with $K_{s b}$, and the influence of the term with $C_{s b}$ is also small and difficult to be determined, so this term with $M_{s b}$ and $C_{s b}$ is not taken into account. Then, equation (11) can be written as

$$
M_{s s} \ddot{u}_{s}+C_{s s} \dot{u}_{s}+K_{s s} u_{s}=F_{s}-K_{s b} u_{b} .
$$

3.3. Criteria for Train Running Safety. In the current Chinese codes, the criteria for evaluating train running safety include derailment factor, offload factor, and lateral wheel-rail force [28]. The three train running safety indices can be obtained by in situ measurements or from train-bridge coupling dynamic analysis.

3.3.1. Derailment Factor. Derailment factor is an index to evaluate the safety of the vehicle wheel against derailment.
Derailment factor is defined as $Q / P$, the ratio of the lateral force to the dynamic wheel load. The maximum wheel derailment factor $(Q / P)$ from all the wheel sets of a train is calculated as [29]

$$
\frac{Q}{P}=\operatorname{Max}\left(\frac{Q_{i}}{P_{i}}\right), \quad i=1, n,
$$

where $Q_{i}$ and $P_{i}$ are the horizontal and vertical forces of the $i$ th wheel set and $n$ means the total number of wheel sets for the train.

The limits for derailment factor are given in various countries as follows: (1) Western Europe: $Q / P<0.8$, (2) Japan: $Q / P<0.8$, (3) North America: $Q / P<1.0$, and (4) China: $Q / P<0.8$. In this study, the China standards are adopted to evaluate the train derailment factor.

3.3.2. Offload Factor. The offload factor is used to check whether the vehicle will derail due to overlarge offload at one side of the wheel set. It is adopted as an important index in evaluating the vertical dynamic performance of the trainbridge system. Offload factor is defined as $\Delta P / \bar{P}$, the ratio of wheel load reduction at the offloaded side to the average load of the two wheels, in which 


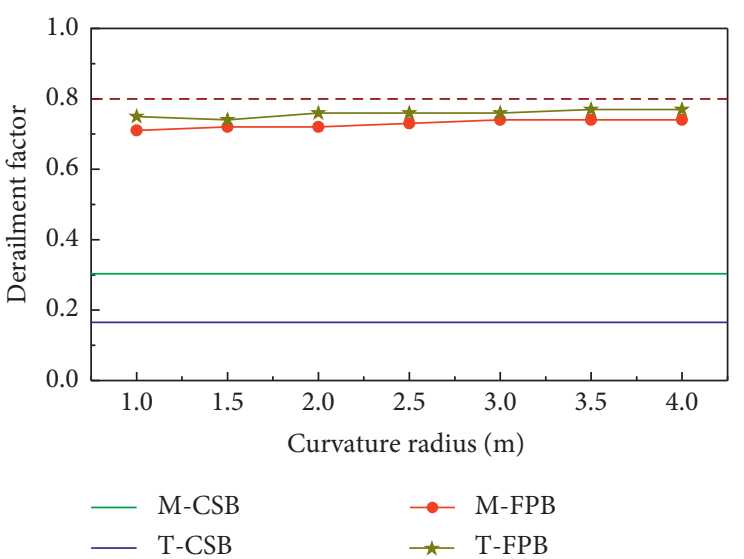

(a)

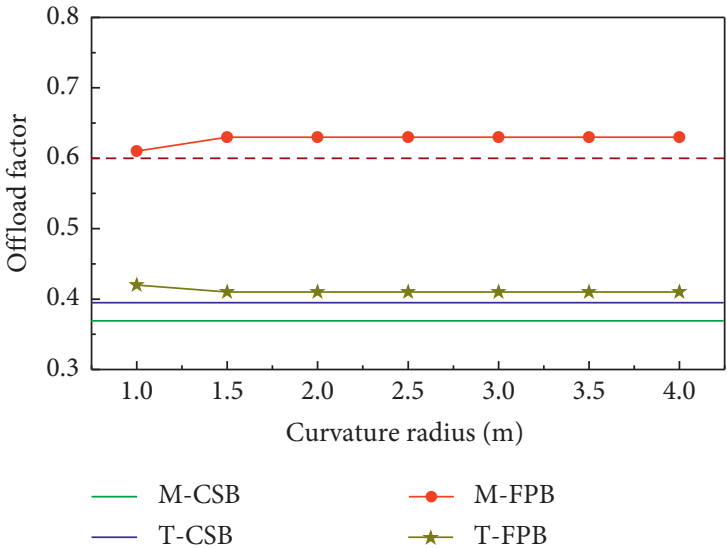

(b)

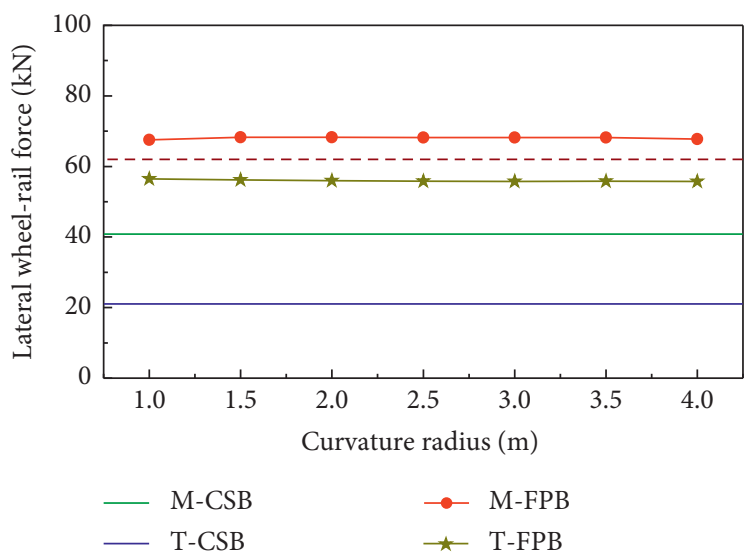

(c)

FIGURE 10: Distributions of running safety indices of the train versus curvature radius. (a) Derailment factor. (b) Offload factor. (c) Lateral wheel-rail force.

$$
\begin{aligned}
\bar{P} & =\frac{\left(P_{1}+P_{2}\right)}{2}, \\
\Delta P & =\bar{P}-P_{i} \quad(i=1,2),
\end{aligned}
$$

where $P_{1}$ and $P_{2}$ are the static loads of the wheels on both sides of the train, respectively. When the train is unbiased, $\bar{P}=P_{1}=P_{2}$, while $P_{i}$ is the wheel load on the unloading side of the train.

The limits for offload factor of HSR in China are given as

$$
\left\{\begin{array}{l}
\frac{\Delta P}{\bar{P}} \leq 0.65, \text { hazard limit, } \\
\frac{\Delta P}{\bar{P}} \leq 0.60, \quad \text { allowable limit. }
\end{array}\right.
$$

The limit for offload factor adopted in this study is $\Delta P / \bar{P} \leq 0.60$.

3.3.3. Lateral Wheel-Rail Force. The criterion for wheel-rail lateral force is recommended to evaluate whether it will enlarge the gauge or seriously deform the track. The lateral wheel-rail force can be interpreted as the sum of the wheel lateral forces on both sides of the wheel set. China's standard limits for lateral wheel-rail force are given as

$$
Q \leq 10+\frac{P_{0}}{3}
$$

where $Q$ is the lateral wheel-rail force and $P_{0}$ is the static wheel-rail load of the wheel set and the unit is $\mathrm{kN}$. In this study, $Q \leq 62 \mathrm{kN}$ is adopted as the limit value of the lateral wheel-rail force.

\section{Realization of Numerical Simulation}

Train-bridge coupling vibration involves two subsystems of the vehicle and the bridge. In the preprocessing of ANSYS, the bridge model can be saved as a cdb file that only contain the node information of elements, and the subfile that contains the stiffness matrix and mass matrix information of the bridge is generated by the substructure analysis. Then, the subfile is imported into SIMPACK to generate the (.fbi) file of the flexible body which can be used to realize the girder-rail relationship with rails. The simulation of FPB is realized through the No.104 force element of SIMPACK which has the characteristics of nonlinear elasticity as displayed in Figure 5, and the CSB is simulated master-slave 


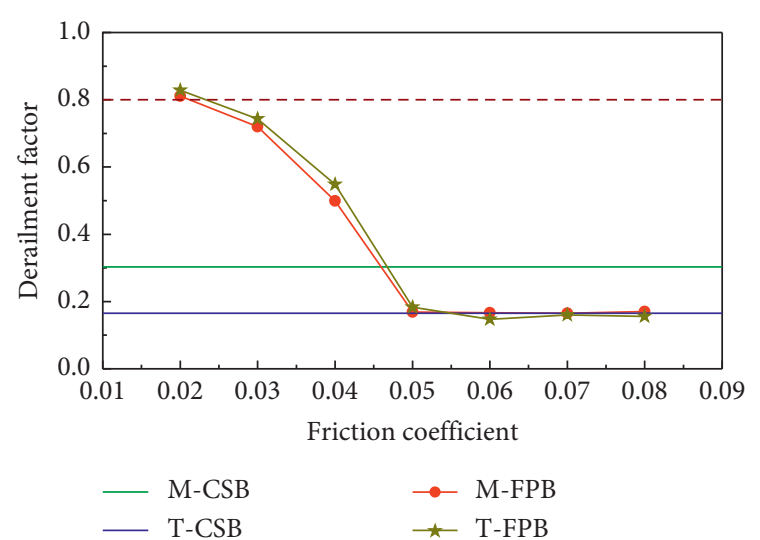

(a)

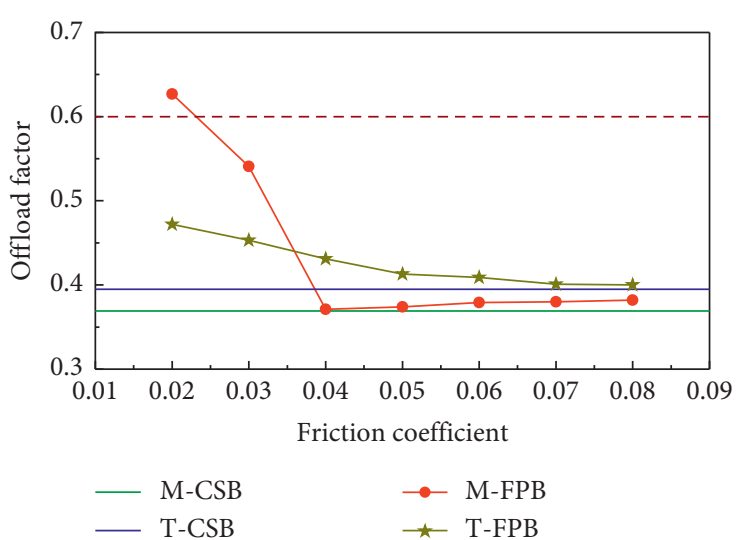

(b)

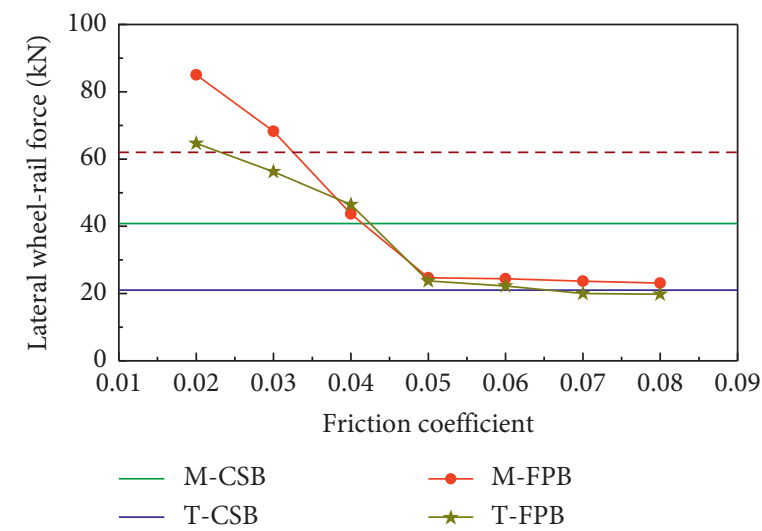

(c)

FIGURE 11: Distributions of running safety indices of the train versus friction coefficient. (a) Derailment factor. (b) Offload factor. (c) Lateral wheel-rail force.

restraint in ANSYS. In the SIMPACK, the rigid bodies and suspension systems of the train model are simulated by the bodies, hinge joints, force element, and other elements; the flexible rail model is established by the flexible rail information file invoking and fitting the standard input file of the flexible body, and the rail irregularity is defined by incentive factors and generated by the track module; and the seismic excitation is realized by inputting the u-vectors of the acceleration, velocity, and displacement time histories of the seismic wave to a special virtual rigid body with the 35 th hinge that is adopted to simulate the pier foundation. The dynamic interaction between the vehicle and the bridge is realized by data exchange at discrete information points of the wheel-rail contact surface [30].

In the calculation of coupling vibration of the trainbridge system, the vehicle and the bridge are regarded as two systems and solved in turn iteration in the time step. The absolute error of the solver is $1 \times 10^{-5}$, and the calculation time step is $0.0001 \mathrm{~s}$. The motion equations of the rigid body model and the flexible body model are solved by different algorithms. The rigid body model is solved by the backward differentiation formula, while the flexible body is solved by the mode superposition method. In this paper, Hertz nonlinear contact theory is used to calculate the wheel/rail normal force, and the simplified Kalker creep assumption is used to calculate the wheel/rail tangential creep force [31].

\section{Case Study}

5.1. Parameters Used in Calculation. Multispan simply supported girder bridges are often constructed in HSR. A $5 \times 32 \mathrm{~m}$ double-track PC box-girders with piers of $16 \mathrm{~m}$ in height is selected in this case study, as shown in Figure 7. The absolute global coordinate system is adopted, in which the $x$-axis is defined as the longitudinal direction of the bridge, the $y$-axis the lateral direction, and the $z$-axis the vertical direction. The length of each box-girder is $32.6 \mathrm{~m}$, the width of the girder is $13.4 \mathrm{~m}$ at the top and $5.75 \mathrm{~m}$ at the bottom, and the height is $3.05 \mathrm{~m}$. The piers have a full-height hollow rectangular cross section of $6.8 \mathrm{~m}$ (lateral bridge direction) $\times 3.3 \mathrm{~m}$ (along the bridge direction), with $0.5 \mathrm{~m}$ wall thickness. C50 concrete and C30 concrete are adopted for the girders and piers, respectively. The load of accessory structures is $184 \mathrm{kN} / \mathrm{m}$. The damping ratio of the bridge structure is assumed to be $2 \%$ for all interested modes. The bridge is equipped with FPBs for seismic isolation. The modal characteristics of the bridge are analyzed, and the first 300 modes are used in the dynamic analysis, and the integration time step is $10^{-4} \mathrm{~s}$. 


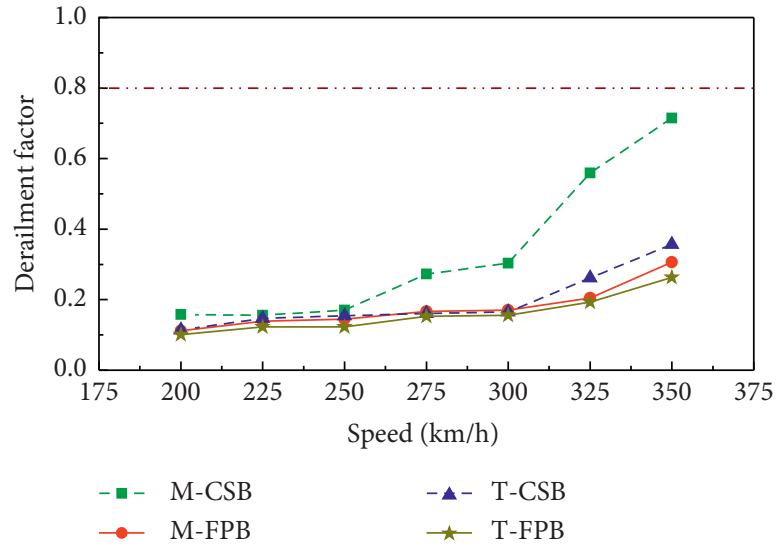

(a)

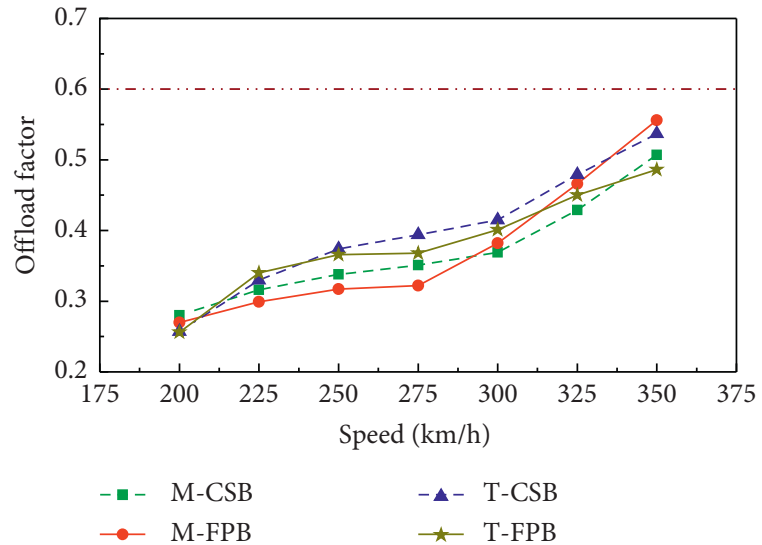

(b)

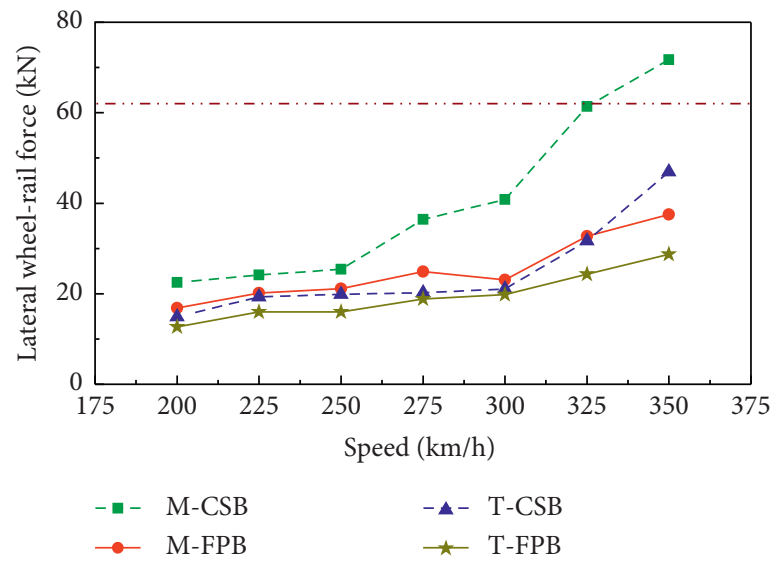

(c)

FIGURE 12: Distributions of running safety indices of the train versus train speed. (a) Derailment factor. (b) Offload factor. (c) Lateral wheelrail force.

The JIS-60-kg type rail with a length of $743.4 \mathrm{~m}$ is adopted in the case. The lateral stiffness, vertical stiffness, lateral damping, and vertical damping of fasteners are $0.6 \times 10^{8} \mathrm{~N} / \mathrm{m}, \quad 1.2 \times 10^{8} \mathrm{~N} / \mathrm{m}, \quad 1.2 \times 10^{5} \mathrm{~N} \cdot \mathrm{S} / \mathrm{m}, \quad$ and $1.5 \times 10^{5} \mathrm{~N} \cdot \mathrm{S} / \mathrm{m}$, respectively. In this study, the German low disturbing track spectra are selected as the rail irregularities [32], with wavelengths ranging from $1 \mathrm{~m}$ to $120 \mathrm{~m}$ and a space step of 0.2 meters, as shown in Figure 8. The frequency number of the track spectrum is set to 2000 , and the frequency range is $100-200 \mathrm{~Hz}$.

As shown in Figure 6, the modified El Centro seismic wave is applied to the pier foundation as lateral earthquake actions, and half magnitude of them are as the vertical earthquake actions [28]. The seismic intensity is described by the amplitude of lateral bridge acceleration, and the seismic intensity is $0.1 \mathrm{~g}$ ( $g$ is the gravity acceleration, $\mathrm{g}=9.8 \mathrm{~m} / \mathrm{s}^{2}$ ). It is assumed that the earthquake occurs when the train moves just onto the bridge.

The ICE3 high-speed train is used in the case [28], which consists of eight vehicles, with the first, third, fifth, and seventh vehicles being motor cars (MC) and the second, fourth, sixth, and eighth vehicles being trailer cars (TC). The length of each car is 25 meters. The main parameters of the vehicle are shown in Table 1 [33]. The trains run at a speed of
$300 \mathrm{~km} / \mathrm{h}$. Each vehicle is treated as an independent dynamic system without modeling the coupling device, considering the analytical conditions that the train is running on a straight line and the inertia force due to the ground motion is simultaneously acting on the cars without phase difference.

5.2. Characteristic of Seismic Isolation of FPB. To analyze the characteristic of seismic isolation of FPB, the dynamic responses of the coupled train-bridge with the isolation of FPB and CSB are calculated. According the "TJGZ-FPB" that has been applied in engineering at present [34], the parameters of FPB in the case are given as the friction coefficient is 0.03 , and the curvature radius is $1.5 \mathrm{~m}$. Displayed in Figure 9 are the derailment factor, offload factor, and lateral wheel-rail force time histories of the first wheel set of the train running at $300 \mathrm{~km} / \mathrm{h}$, in which $3.18 \mathrm{~s}$ is the time when the train just got on the bridge.

As illustrated in Figure 9, when the train arrived on the bridge, FPB increased the derailment factor of the first wheel set of the train from 0.146 to 0.354 at the moment of the earthquake occurred, which is about 2.21 times of that of CSB and increased the lateral wheel-rail force of the train 


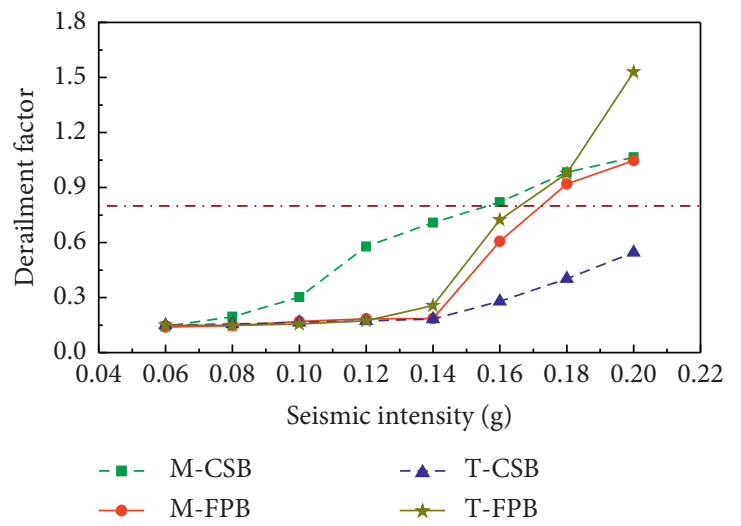

(a)

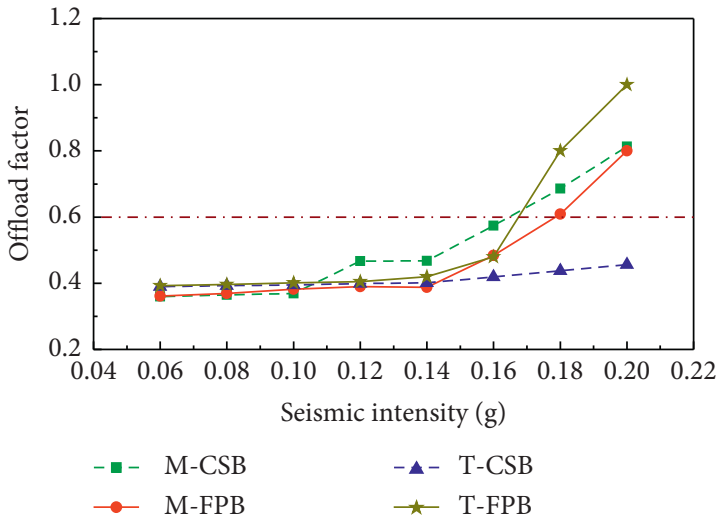

(b)

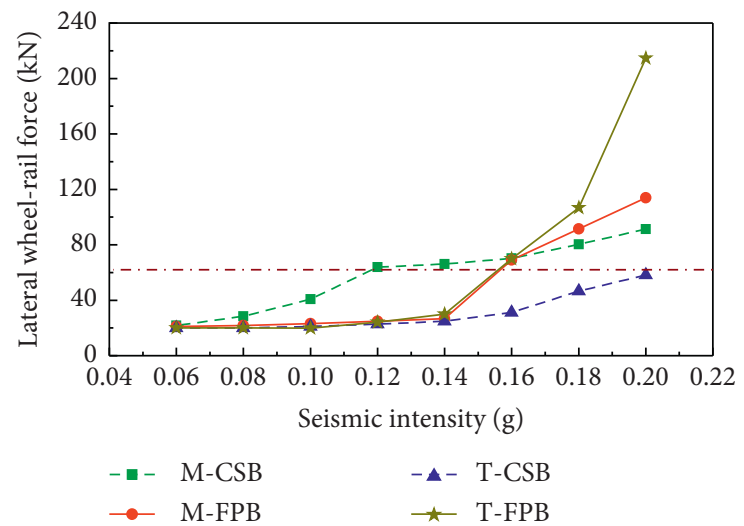

(c)

FIGURE 13: Distributions of running safety indices of the train versus seismic intensity. (a) Derailment factor. (b) Offload factor. (c) Lateral wheel-rail force.

from $19.8 \mathrm{kN}$ to $45.0 \mathrm{kN}$, which is about 2.27 times of that of CSB. Although FPB increased the derailment factor and lateral wheel-rail force of trains, the value still meets the limits of code. There is no significant difference between FPB and CBS in the offload factor of the train.

5.3. Sensitivity of FPB Parameters on Dynamic Responses of the Train. As mentioned previously, the key factors that affected the seismic performance of FPB are the friction coefficient and the curvature radius. In this section, with the same bridge, seismic intensity, and rail irregularity parameters given in Section 5.1, a further calculation is performed by extending the range of friction coefficient and curvature radius of FPB to study the sensitivity of them on dynamic responses of the train under seismic loads. The maximum values of running safety indices, which are taken from the corresponding time histories of all wheel sets during passage of the train on the bridge, are used to compare and evaluate the safety of trains. The dynamic responses of the coupled vehicle-bridge with CSB under earthquake are also calculated.

5.3.1. Sensitivity of Curvature Radius. The curvature radius range is extended from $1 \mathrm{~m}$ to $4 \mathrm{~m}$ with an interval of $0.5 \mathrm{~m}$, and the friction coefficient remains unchanged at 0.03 .
Displayed in Figure 10 are the distribution curves of the running safety indices of trains versus curvature radius of FPB. The horizontal dashed lines represent the related allowance values.

As illustrated in Figure 10, the derailment factor, offload factor, and lateral wheel-rail force of the train change very slightly along with the increase of curvature radius of FPB. The results illustrate that the dynamic responses of trains are insensitive to the curvature radius of FPB. FPB with a friction coefficient of 0.03 increased the dynamic responses of the train. The maximum derailment factor, offload factor, and lateral wheel-rail force of the train increased to 4.61 times, 1.71 times, and 2.65 times of those of CSB, respectively. The maximum offload factor and lateral wheel-rail force of MC exceed the allowance values, other dynamic indexes of trains below the allowance values.

5.3.2. Sensitivity of Friction Coefficient. The range of the friction coefficient is 0.02 to 0.08 with an interval of 0.01 , and the curvature radius is kept at $1.5 \mathrm{~m}$. Displayed in Figure 11 are the distribution curves of the running safety indices of trains versus friction coefficient of FPB. The horizontal dashed lines are the related allowance values.

As illustrated in Figure 11, the derailment factor, offload factor, and lateral wheel-rail force of the train decreased 


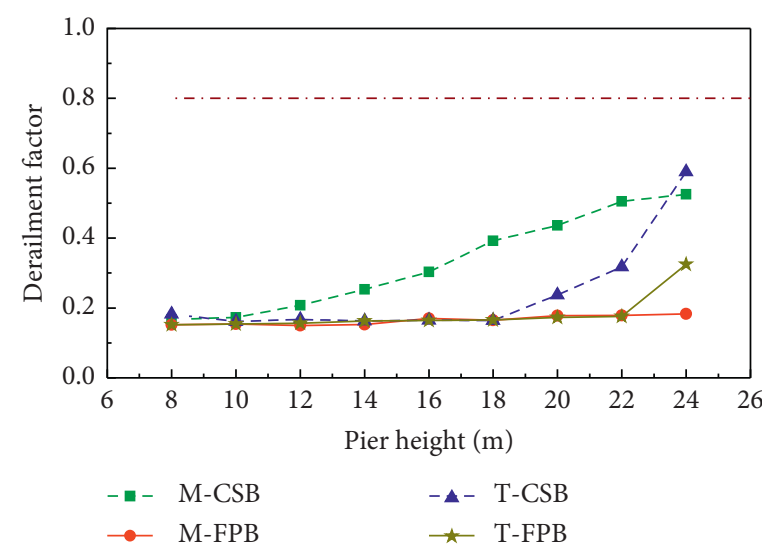

(a)

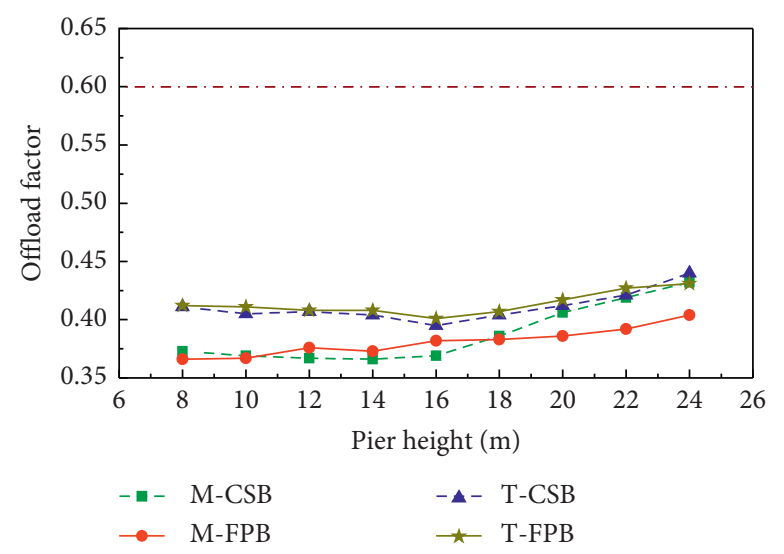

(b)

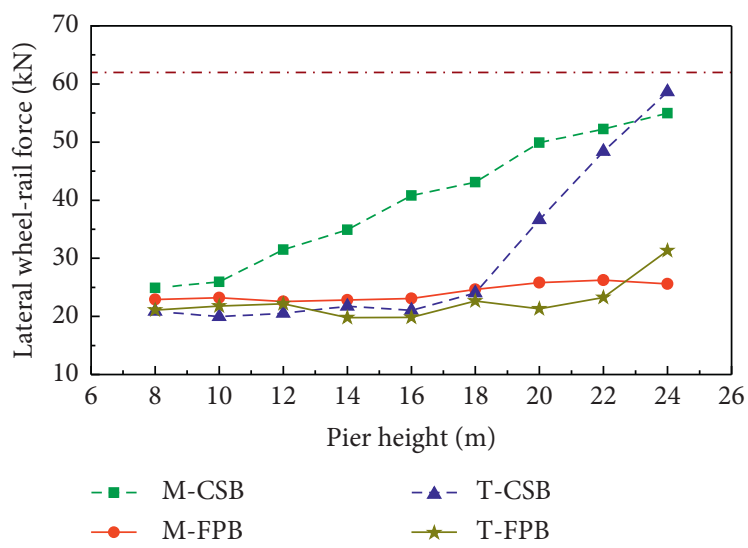

(c)

Figure 14: Distributions of running safety indices of the train versus pier height. (a) Derailment factor. (b) Offload factor. (c) Lateral wheelrail force.

rapidly along with the increase of friction coefficient of FPB below 0.05 , and those of trains change very slightly when it exceeds 0.05 . When the friction coefficient of FPB is less than 0.05 , the dynamic responses of trains exceed the allowance values, which is dangerous to the safety of running trains. When the friction coefficient reaches 0.05 , FPB can reduce the dynamic responses of trains, and the maximum derailment factor, offload factor, and lateral wheel-rail force of the train decreased to $19 \%, 61 \%$, and $27 \%$ of those of CSB, respectively. These results illustrate that the dynamic responses of the train are sensitive to the friction coefficient of FPB. For the sake of train safety, the friction coefficient of FPB should be more than 0.05 .

5.4. Analysis of Influencing Factors of Dynamic Response of Trains. Section 5.3.2 shows that the friction coefficient of FPB should be more than 0.05 in seismic isolation design of the simply supported girder bridge of HSR. In this section, with the same bridge and rail irregularity parameters given in Section 5.1, the friction coefficient and curvature radius of FPB are given as 0.05 and $1.5 \mathrm{~m}$, respectively. The dynamic response of the high-speed train traveling on the bridge with isolation of $\mathrm{FPB}$ or with CSB under earthquake is investigated by considering different train speeds, seismic intensities, and pier heights.

5.4.1. Influence of Train Speed. The parameters of the bridge, FPB, rail irregularity, seismic intensity, and the ICE3 train are kept unchanged; the train speed is varied from $200 \mathrm{~km} / \mathrm{h}$ to $350 \mathrm{~km} / \mathrm{h}$ with an interval of $25 \mathrm{~km} / \mathrm{h}$. The distribution curves of the running safety indices of train speed are depicted in Figure 12, in which the horizontal dashed lines represent the related allowance values. As illustrated in Figure 12, whether CSB or FPB is considered, the derailment factor, offload factor, and lateral wheel-rail force of the train increase slowly along with the increase of train speed below $300 \mathrm{~km} / \mathrm{h}$ and those of the train increase rapidly when it exceeds $300 \mathrm{~km} / \mathrm{h}$. When the train speed is more than $325 \mathrm{~km} / \mathrm{h}$, the maximum lateral wheel-rail force of the train exceeds the allowable value. The derailment factor and lateral wheel-rail force of the train can be reduced by FPB replacing CSB. Generally, the faster the train speed, the better the effect of FPB. When the train speed reaches $350 \mathrm{~km} / \mathrm{h}$, the maximum derailment factor and lateral wheel-rail force of train are reduced to $43 \%$ and $52 \%$ of those of CSB, respectively. FPB can reduce the offload factor of trains with the 
train speed below $325 \mathrm{~km} / \mathrm{h}$; however, FPB will increase the offload factor of trains when it exceeds $325 \mathrm{~km} / \mathrm{h}$.

5.4.2. Influence of Seismic Intensity. Keeping the parameters of the bridge, FPB, rail irregularity, seismic intensity, and trains unchanged and the trains to run at $300 \mathrm{~km} / \mathrm{h}$, the influence of seismic intensity on dynamic responses of running trains is analyzed by considering the seismic intensities from $0.06 \mathrm{~g}$ to $0.20 \mathrm{~g}$ with an interval of $0.02 \mathrm{~g}$. The distribution curves of the maximum running safety indices of trains versus seismic intensity are depicted in Figure 13, in which the horizontal dashed lines are the related allowance values.

As illustrated in Figure 13, the dynamic responses of running trains increased along with the increase of seismic intensity whether CSB or FPB is considered. When the seismic intensity is below $0.14 \mathrm{~g}$, after FPB instead of CSB, the derailment factor, offload factor, and lateral wheel-rail force of the train increased slowly along with the increase of seismic intensity, and the maximum derailment factor, offload factor, and lateral wheel-rail force of $\mathrm{MC}$ are reduced to $25 \%, 83 \%$, and $40 \%$ of those of CSB, respectively. FPB has no obvious effect on reducing the dynamic responses of TC. When the seismic intensity exceeds $0.14 \mathrm{~g}$, the dynamic responses of the train increased rapidly and exceed the allowable value; FPB increased the dynamic responses of the train and raised the risk and probability of derailment of the train.

5.4.3. Influence of Pier Height. Depicted in Figure 14 are the distribution curves of the maximum running safety indices of trains versus pier height by considering pier heights varied from $8 \mathrm{~m}$ to $24 \mathrm{~m}$ with an interval of $2 \mathrm{~m}$, in which the horizontal dashed lines represent the related allowance values. The parameters of FPB, rail irregularity, and the ICE3 train remain unchanged, the seismic intensity is $0.1 \mathrm{~g}$, and the train runs at $300 \mathrm{~km} / \mathrm{h}$.

From the figures, it can be seen that when CSB is considered, the derailment factor, lateral wheel-rail force, and offload factor of the train increased along with the increase of pier height, especially when the pier height exceeds $18 \mathrm{~m}$, the dynamic response of the train increases rapidly. When pier heights varied from $8 \mathrm{~m}$ to $24 \mathrm{~m}$, the value of dynamic response of trains is all below the allowable value. Dynamic response of the trains can be reduced by FPB instead of CSB; the higher the pier, the better the effect of FPB. When the pier height reaches $24 \mathrm{~m}$, the maximum derailment factor and lateral wheel-rail force of the train are decreased to $25 \%$ and $50 \%$ of those of CSB, respectively. FPB has no obvious effect on reducing offload factor of trains.

\section{Conclusion}

The following conclusions can be drawn from the study:

(1) In the calculation of coupling vibration of the trainbridge system, the vehicle and the bridge are regarded as two systems and solved in turn iteration in the time step. The motion equations of the rigid body model and the flexible body model can be solved by the backward differentiation formula and the mode superposition method, respectively.

(2) The friction coefficient of FPB has an obvious effect on the dynamic responses of the running train. The dynamic responses of the train decrease rapidly along with the increase of friction coefficient of FPB below 0.05 , while those of the train change very slightly when it exceeds 0.05 . For the safety of train operation, it is suggested that the friction coefficient should be more than 0.05 in the design of FPB for the high-speed railway simple-supported girder bridge.

(3) The dynamic responses of the train are insensitive to the curvature radius of FPB. The curvature radius of FPB can only be selected according to the stiffness requirement of the bearing.

(4) The derailment factor, lateral wheel-rail force, and offload factor of trains increased along with the increase of the train speed, the seismic intensity, and the pier height. FPB can reduce the dynamic response of the train; the faster the train speed and the higher the pier, the greater the effect of FPB. However, FPB may increase the dynamic response of the train when the seismic intensity exceeds $0.14 \mathrm{~g}$.

\section{Data Availability}

The data generated during and/or analyzed during the current study are available from the corresponding author on reasonable request.

\section{Conflicts of Interest}

The authors declare that they have no conflicts of interest.

\section{Acknowledgments}

This study was supported by the National Natural Science Foundation of China (Project no. 51078356) and the Major Technology Research and Development Program of the Ministry of Railway of China (Project no. 2008G031-Q), to which the authors are most grateful.

\section{References}

[1] 2019, http://finance.sina.com.cn/roll/2019-01-02/docihqfskcn3310957.shtml.

[2] Q. Zeng and E. G. Dimitrakopoulos, "Seismic response analysis of an interacting curved bridge-train system under frequent earthquakes," Earthquake Engineering \& Structural Dynamics, vol. 45, no. 7, pp. 1129-1148, 2016.

[3] M. Ogura, "The Niigata Chuetsu earthquake-railway response and reconstruction," Japan Railway and Transport Review, vol. 43, no. 44, pp. 46-63, 2006.

[4] S. H. Ju, "Nonlinear analysis of high-speed trains moving on bridges during earthquakes," Nonlinear Dynamics, vol. 69, no. 1-2, pp. 173-183, 2012.

[5] 2016, http://www.xinhuanet.com/world/2016-04/15/c_ 128898878.htm. 
[6] S. H. Ju, "Improvement of bridge structures to increase the safety of moving trains during earthquakes," Engineering Structures, vol. 56, pp. 501-508, 2013.

[7] L. K. Chen, Seismic responses of high-speed railway trainballastless track-bridge system and train-running safety during earthquake, Doctoral dissertation, Central South University, Changsha, China, 2012, in Chinese.

[8] H. Xia, Y. Han, N. Zhang, and W. Guo, "Dynamic analysis of train-bridge system subjected to non-uniform seismic excitations," Earthquake Engineering \& Structural Dynamics, vol. 35, no. 12, pp. 1563-1579, 2006.

[9] K. Nishimura, Y. Terumichi, T. Morimura, and K. Sogabe, "Analytical study on the safety of high speed railway vehicle on excited tracks," Journal of System Design and Dynamics, vol. 4, no. 1, pp. 211-225, 2010.

[10] H. J. Lei, X. Z. Li, and D. J. Liu, "Train running safety analysis of high-pier rigid-frame bridge under earthquake action," Earthquake Engineering and Engineering Vibration, vol. 34, no. 5, pp. 87-93, 2014.

[11] L. Su, G. Ahmadi, and I. G. Tadjbakhsh, "Comparative study of base isolation systems," Journal of Engineering Mechanics, vol. 115, no. 9, pp. 1976-1992, 1989.

[12] V. A. Zayas, S. S. Low, and S. A. Mahin, "A simple pendulum technique for achieving seismic isolation," Earthquake Spectra, vol. 6, no. 2, pp. 317-333, 1990.

[13] G. Mosqueda, A. S. Whittaker, and G. L. Fenves, "Characterization and modeling of friction pendulum bearings subjected to multiple components of excitation," Journal of Structural Engineering, vol. 130, no. 3, pp. 433-442, 2004.

[14] L. Landi, G. Grazi, and P. P. Diotallevi, "Comparison of different models for friction pendulum isolators in structures subjected to horizontal and vertical ground motions," Soil Dynamics and Earthquake Engineering, vol. 81, pp. 75-83, 2016.

[15] P. Castaldo and R. Lo Priore, "Seismic performance assessment of isolated bridges for different limit states," Journal of Civil Structural Health Monitoring, vol. 8, no. 1, pp. 17-32, 2018.

[16] C. Wang, J. Zhao, L. Zhu, and Y. Bao, "Effects of vertical excitation on the seismic performance of a seismically isolated bridge with sliding friction bearings," Earthquake Engineering and Engineering Vibration, vol. 15, no. 1, pp. 187-196, 2016.

[17] S. Purnachandra, "Seismic control of benchmark cable-stayed bridges using variable friction pendulum isolator," in $\mathrm{Ad}$ vances in Structural Engineering, pp. 1271-1282, Springer, Berlin, Germany, 2015.

[18] Y. L. Zhan, L. Zhang, Q. Zhang et al., "Effects of parameters of friction pendulum bearings on seismic response of seismically isolated bridge," Bridge Construction, vol. 48, no. 3, pp. 45-49, 2018, in Chinese.

[19] C. Y. Zhang, T. Y. Zhong, and H. Y. Yang, "A study on seismic energy responses of a continuous girder bridge isolated by a friction pendulum system," Journal of Vibration and Shock, vol. 36, no. 16, pp. 63-67, 2017, in Chinese.

[20] W. M. Zhai, Vehicle-Track Coupling Dynamics, China Railway Press, Beijing, China, 3rd edition, 2007, in Chinese.

[21] Y. Zhou and P. Chen, "Shaking table tests and numerical studies on the effect of viscous dampers on an isolated RC building by friction pendulum bearings," Soil Dynamics and Earthquake Engineering, vol. 100, pp. 330-344, 2017.

[22] W. M. Zhai, Vehicle-Track Coupled Dynamics, China Railway Press, Beijing, China, 2nd edition, 2002, in Chinese.

[23] Z. M. Deng, X. R. Guo, and Z. Y. Zhang, "Coupled vibration of train-bridge system of steel truss bridge with seismic effect,"
Journal of Central South University (Science and Technology), vol. 42, no. 1, pp. 184-191, 2011, in Chinese.

[24] Y. N. Zhou, W. B. Zhang, and H. Y. Yu, "Analysis of longperiod error for accelerograms recorded by digital seismographs," Earthquake Engineering and Engineering Vibration, vol. 17, no. 2, pp. 1-9, 1997, in Chinese.

[25] Y. T. Zhang and Y. M. Jia, "Analysis and program implementation of least squares polynomial curve fitting," Computer and Digital Engineering, vol. 45, no. 4, pp. 637-639, 2017, in Chinese.

[26] Q. Y. Zeng and X. R. Guo, Theory and Application of Vibration Analysis for Time-Varying System of Train and Bridge, China Railway Press, Beijing, China, 1999, in Chinese.

[27] Z. H. Wang, Study of the effect of friction pendulum bearing on coupled vibration of train-track-bridge under earthquakes, M.S. thesis, Central South University, Changsha, China, 2018, in Chinese.

[28] W. M. Zhai and H. Xia, Train-Track-Bridge Dynamic Interaction: Theory and Engineering Application, Science Press, Beijing, China, 2011, in Chinese.

[29] J. Xiang and Q. Y. Zeng, "A study on mechanical mechanism of train derailment and preventive measures for derailment," Vehicle System Dynamics, vol. 43, no. 2, pp. 121-147, 2005.

[30] W. Zhu, T. Qi, and L. Jia, "Dynamic performance analysis of vehicle-bridge system for a cable-stayed bridge with steel truss girder based on SIMPACK," Railway Standard Design, vol. 58, no. 7, pp. 89-94, 2014, in Chinese.

[31] X. T. Du, Y. L. Xu, and H. Xia, "Dynamic interaction of bridge-train system under non-uniform seismic ground motion," Earthquake Engineering \& Structural Dynamics, vol. 41, no. 1, pp. 139-157, 2012.

[32] N. Zhang, H. Xia, and G. De Roeck, "Dynamic analysis of a train-bridge system under multi-support seismic excitations," Journal of Mechanical Science and Technology, vol. 24, no. 11, pp. 2181-2188, 2010.

[33] C. X. Chen, "Vibration response analysis of train-rail-bridge coupling system for high-speed train intersection under cross wind," M.S. thesis, Central South University, Changsha, China, 2019.

[34] X. L. Zhen and Y. X. Jin, "Design and seismic isolation performance analysis of friction pendulum bearings," Journal of Railway Engineering Society, vol. 4, pp. 81-87, 2014, in Chinese. 